\title{
Dowling-Degos Disease: Case Report and Review of the Literature
}

\author{
Aleksandra Batycka-Baran ${ }^{\mathrm{a}}$ Wojciech Baran ${ }^{\mathrm{a}}$ Anita Hryncewicz-Gwozdz \\ Walter Burgdorf ${ }^{b}$ \\ ${ }^{a}$ Department of Dermatology, Venereology and Allergology, Wroclaw Medical University, Wroclaw, Poland; \\ ${ }^{b}$ Department of Dermatology, Ludwig Maximilian University, Munich, Germany
}

\section{Key Words}

Reticulate pigmentation - Axillary and inguinal pigmentations - Dowling-Degos disease

\begin{abstract}
Dowling-Degos disease (DDD) is an unusual pigmentary disorder usually caused by mutations in keratin 5. A 44-year-old woman in good general health presented due to the recent appearance of numerous pigmented macules on her axillary and anogenital skin. A biopsy showed lacy, finger-like epidermal extensions into the dermis which were heavily pigmented and associated with tiny cysts or dilated follicles. We view DDD as part of a spectrum of disorders which are morphologically related but vary in location and time of expression. In addition, both the clinical and histological differential diagnostic considerations are extensive.
\end{abstract}

Copyright $\odot 2010$ S. Karger AG, Basel

The terminology of Dowling-Degos disease (DDD) is complex, as many names have been used to describe patients with multiple pigmented macules of the flexures, but the clinical pattern is relatively straightforward. Most patients have only hyperpigmented lesions arranged in a re- ticular pattern. Less often, there may be more widespread pigmented lesions, as well as dark comedo-like lesions on the neck and perioral atrophodermic pits or scars [1]. We present a patient with isolated hyperpigmented macules in the axillae and groins without other skin abnormalities. Then, we discuss the classification of DDD and its lengthy differential-diagnostic considerations.

\section{Case Report}

A 44-year-old woman was referred to our department in October 2008 for evaluation of progressive macular pigmentations in her axillae and anogenital area. The dark macules had appeared insidiously and were first noticed 1 year prior to the referral. Over the last 3 months, the lesions had become larger, and new ones had appeared. The patient's history revealed pulmonary sarcoidosis, diagnosed in 2007 but apparently in remission, without treatment. The patient reported no similar lesions in her parents, siblings or children. Physical examination revealed a healthy woman with skin type 2 who had numerous small, round or oval, deeply pigmented, dark brown macules. These were approximately $2-4 \mathrm{~mm}$ in diameter and lo- cated in her axillae (fig. 1). The macules were arranged in a net-like pattern. On the vulva and perineal skin, similar macules were present but with a tendency toward confluence (fig. 2). No scaling was present. There were no plugged follicles or periorificial pits. The remainder of the skin, its appendages and the mucous membranes were unaffected.

Histologic examination of one of the perineal macules (fig. 3) revealed a focal proliferation of epithelium with narrow tongues of basaloid epithelium extending into the dermis. Many of the lacy strands of epithelium were only 2 cell layers thick. There were large amounts of melanin, especially in the basal layer, but there was no obvious increase in the number of melanocytes, and there were definitely no nests of melanocytes. Some small intraepithelial horn inclusions or pseudocysts were present. In the upper dermis, there was a mild inflammatory reaction with the presence of some melanophages. Laboratory studies, including skull and chest radiographs, an abdomen sonography, an electrocardiography, biochemical function tests of the liver, pancreas and kidney, a urinalysis and a neurological examination, were all normal or noncontributory. We were unable to obtain genetic studies on the patient.

\section{KARGER}

Fax +4161306 1234 E-Mail karger@karger.ch www.karger.com www.karger.com/drm
Wojciech Baran

Department of Dermatology, Venereology and Allergology

Wroclaw Medical University, ul. Chalubinskiego 1

PL-50368 Wroclaw (Poland)

Tel. +48 713270 941, Fax +48 713270 942, E-Mail wbaran@mp.pl 
1

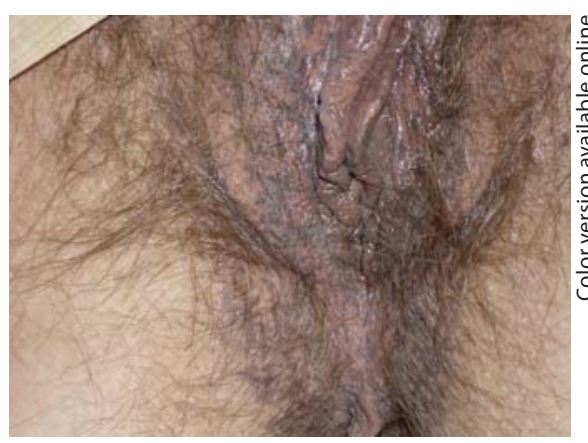

$\stackrel{\Perp}{\stackrel{2}{2}} \mathbf{2}$

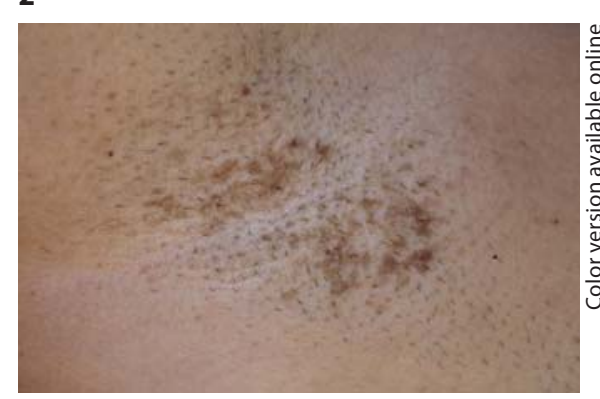

3

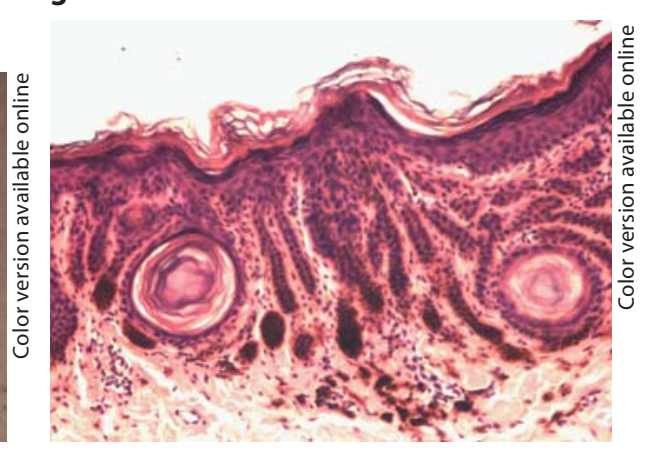

Fig. 1. Genital area. Numerous smooth-surfaced, dark-colored macules on the vulva and surrounding skin of perineum.

Fig. 2. Axillary fossa. Pigmented net-like macules.

Fig. 3. Specimen from the perineal area. Focal proliferation of the epidermis with large amounts of melanin, particularly in the basal cells, and horn inclusions. In the dermis, melanophages and melanin deposits are scattered outside the cells. HE. Original magnification $\times 100$.

\section{Discussion}

The history of this disorder is long and confusing. If one defines the absolute diagnostic criteria as (1) pigmented macules in the flexures with a reticulate (interconnecting, lacy or net-like) pattern and (2) histological evidence of epithelial tongues or strands extending downward into the dermis with an increased amount of melanin but no increase in the number of melanocytes, then the first person to describe DDD was, in all likelihood, Behçet [2] in 1932. (The French spelling of his name is Behdjet.) Behçet considered a patient displaying such symptoms to have a variant of acanthosis nigricans, but with a low risk of associated tumors. Dowling and Freudenthal [3] also described a similar case as acanthosis nigricans, while Degos and Ossipowski [4] were the first to introduce the aspect of reticulate pigmentation. Smith et al. [5] emphasized the differences from acanthosis nigricans, while Jones and Grice [6] reviewed related literature and suggested the name DDD. In 2006, Betz et al. [7] identified mutations in keratin 5 in two families with DDD, while, a year later, Planko et al. [8] suggested that both keratin 5 and its partner keratin 14 are involved in vesicle formation and that this could be associated with abnormal epidermal growth and impaired melanin transfer.

Mutations in keratin 5 have also been associated with epidermolysis bullosa simplex (EBS) with mottled pigmentation, as well as with localized and generalized EBS, Dowling-Meara EBS and EBS with migratory erythema $[7,8]$. Mutations in keratin 14 are found in Naegeli-FranceschettiJadassohn syndrome and in dermatopathia pigmentosa reticularis, as well as in both localized and generalized EBS [9].

The 3 main clinical features of DDD have histopathological correlates. The most definite of these is basaloid epithelial hyperplasia with lacy, hyperpigmented dermal extensions and tiny horn cysts, resembling an adenoid seborrheic keratosis, although the lesions are rarely diagnosed as such. The plugged follicles are most common on the neck and are usually confused with pigmented milia or trichofolliculomas. The anetodermic lesions around the mouth resemble those secondary to plugged follicles in keratosis pilaris and related disorders, but a history of preceding hyperkeratotic perioral lesions is usually not given. Perhaps different keratin mutations favor the development of different types of lesions [10].

The first question which arises when considering these disorders is the issue of lumping and splitting, as a befuddling number of names have been attached to a series of disorders which are related either clinically or histologically. The only disease which has unambiguous diagnostic criteria is DDD, with its specific genetic changes. Galli-Galli disease resembles DDD but reveals basal layer acantholysis upon histologic examination $[11,12]$; keratin mutations are found but presumably involve a region of the molecule which is essential to cell-cell adherence [13]. One could speculate that Galli-Galli disease lies somewhere between DDD and EBS with mottled hyperpigmentation. Not all patients have a positive family history and onset in childhood; Behçet's first patient, our patient, a patient reported from our clinic 3 decades ago [14] and many others appear to be sporadic cases. Cases of both DDD [15] and Galli-Galli disease [16] with more extensive cutaneous involvement have been described. Finally, not every patient with clinically unequivocal DDD has keratin 5 mutations.

The next problem is the relationship between reticulate pigmented anomalies of DDD and other disorders [17]. To be precise, reticulate pigmentation should only be used to describe hyperpigmented macules arranged in a net-like or lacy pattern; when hypopigmented lesions are also present, mottled pigmentation is the correct term. In addition, in order to be grouped with DDD, pigmented lesions should show the histological pattern of adenoid seborrheic keratosis. Two syndromes come into consideration here [18]. Online Mendelian Inheritance in Man includes Kitamura acropigmentation as a synonym for DDD. However, there are few, if any, genetic studies, and some published cases do not show epidermal hyperplasia. Haber syndrome is a very rare disorder in which numerous small seborrheic keratoses are associated with rosacea-like dermatitis and multiple basal-cell carcino- 
Table 1. List of differential diagnoses

\begin{tabular}{|c|c|c|c|c|}
\hline Disease & Inh. & Genetic defect & Clinical features & Histologic features \\
\hline DDD & $\begin{array}{l}\mathrm{AD} / \\
\text { spor. }\end{array}$ & Keratin 5 (?14) & $\begin{array}{l}\text { Reticulate hyperpigmented macules in } \\
\text { flexural areas; sometimes dark, plugged } \\
\text { follicles and perioral pitted scars }\end{array}$ & $\begin{array}{l}\text { Tiny adenoid seborrheic keratoses with } \\
\text { increased amount of melanin but normal } \\
\text { numbers of melanocytes; plugged follicles and } \\
\text { pseudocysts }\end{array}$ \\
\hline Galli-Galli & $\begin{array}{l}\mathrm{AD} / \\
\text { spor. }\end{array}$ & Keratin 5 (?14) & Same as DDD & Same as DDD but with suprabasal acantholysis \\
\hline Kitamura & $\mathrm{AD}$ & ? Keratin 5 or 14 & $\begin{array}{l}\text { Acral hyperpigmented macules; sometimes } \\
\text { atrophic lesions or punctate breaks in } \\
\text { dermatoglyphics }\end{array}$ & $\begin{array}{l}\text { Increased amount of basal layer melanin; no } \\
\text { seborrheic-keratosis-like changes }\end{array}$ \\
\hline Dohi & $\mathrm{AD}$ & DSRAD & $\begin{array}{l}\text { Mottled hyper- and hypopigmentation of } \\
\text { distal and dorsal aspects of extremities }\end{array}$ & $\begin{array}{l}\text { Increased amount of basal layer melanin; no } \\
\text { seborrheic-keratosis-like changes }\end{array}$ \\
\hline Neurofibromatosis 1 & $\mathrm{AD}$ & Neurofibromin & $\begin{array}{l}\text { Axillary freckles; café-au-lait-colored } \\
\text { macules; cutaneous neurofibromas }\end{array}$ & $\begin{array}{l}\text { Increased amount of melanin; perhaps giant } \\
\text { melanosomes; no increase in number of } \\
\text { melanocytes }\end{array}$ \\
\hline Acanthosis nigricans & $\begin{array}{l}\mathrm{AD} / \\
\text { spor. }\end{array}$ & Sometimes FGFR3 & $\begin{array}{l}\text { Tiny pigmented papules in axillae, groin } \\
\text { and nape }\end{array}$ & $\begin{array}{l}\text { Church spire papillomatosis with } \\
\text { hyperkeratosis, neither acanthosis nor increase } \\
\text { in amount of melanin }\end{array}$ \\
\hline $\begin{array}{l}\text { Confluent and reticulate } \\
\text { papillomatosis } \\
\text { (Gougerot-Carteaud) }\end{array}$ & Spor. & - & Hyperpigmented patches on trunk & $\begin{array}{l}\text { Church spire papillomatosis with } \\
\text { hyperkeratosis; neither acanthosis nor increase } \\
\text { in amount of melanin; sometimes contains } \\
\text { Malassezia yeasts }\end{array}$ \\
\hline $\begin{array}{l}\text { Mucosal melanotic } \\
\text { macules }\end{array}$ & Spor. & - & $\begin{array}{l}\text { Large, irregular, pigmented macules on oral } \\
\text { or genital mucosa }\end{array}$ & $\begin{array}{l}\text { Transitional epithelium with increased } \\
\text { amount of basal layer pigmentation; no } \\
\text { increase in number of melanocytes }\end{array}$ \\
\hline $\begin{array}{l}\text { Lentiginosis profuse } \\
\text { perigenito-axillaris }\end{array}$ & Unk. & - & $\begin{array}{l}\text { Hyperpigmented macules in axillae and } \\
\text { groin }\end{array}$ & $\begin{array}{l}\text { Increased number of melanocytes and amount } \\
\text { of melanin in the basal layer; no seborrheic- } \\
\text { keratosis-like changes }\end{array}$ \\
\hline $\begin{array}{l}\text { Bannayan-Riley- } \\
\text { Ruvalcaba syndrome }\end{array}$ & $\mathrm{AD}$ & PTEN & $\begin{array}{l}\text { Speckled macules on the penis, along with } \\
\text { multiple hamartomas; part of spectrum of } \\
\text { Cowden syndrome }\end{array}$ & $\begin{array}{l}\text { Increased number of melanocytes and amount } \\
\text { of melanin in the basal layer; no seborrheic- } \\
\text { keratosis-like changes }\end{array}$ \\
\hline
\end{tabular}

Inh. = Inheritance; $\mathrm{AD}=$ autosomal dominant; spor. = sporadic; unk. = unknown; DSRAD = RNA-specific adenosine deaminase gene; PTEN = phosphatase and tensin homolog; FGFR3 = fibroblast growth factor receptor 3.

mas. It is so uncommon that genetic studies have not been done.

The list of differential diagnostic considerations is also long, but can be divided into several groups (table 1). If one starts with hyperpigmented macules or papules as the basic finding, then associated clinical findings and histopathology can rapidly help one sort out the possibilities which include:

(1) Disorders with mottled hyperpigmentation. Two diseases frequently included in the differential diagnosis of DDD are dyschromatosis symmetrica hereditaria (acropigmentation of Dohi) and dyschromatosis universalis hereditaria. Both have hyper- and hypopigmentated macules which, upon histologic analysis, show increased basal layer melanin rather than lacy epithelial strands. Most importantly, they present mutations in nonkeratin genes [19]. Other diseases, such as dyskeratosis congenita and Fanconi anemia, are extremely unlikely to be present with just flexural or genital involvement.

(2) Acanthosis nigricans. Both of the 2 earliest descriptions identified DDD as a variant of acanthosis nigricans. Histologically, acanthosis nigricans is completely different, with exophytic papillomatous epidermal proliferations in church spire patterns and no increase in pigment. Also histologically, acanthosis nigricans is neither acanthotic nor pigmented. In addi- tion, many congenital forms of acanthosis nigricans result from mutations in fibroblast growth factor receptor 3, while acquired forms are related to excessive stimulation of this and other receptors by insulin-like growth factor-1, fibroblast growth factor- $\alpha$ and other epidermal growth factors, medications or tumor-related factors [15].

(3) Confluent and reticulate papillomatosis or Gougerot-Carteaud disease. This disorder presents with scaly or velvety brown macules, patches and plaques, which can be reticulated and favor the trunk, but may also involve the axillae and neck, in which case they are easily confused with DDD. Histologically, the le- 
sions resemble acanthosis nigricans, with a church spire pattern and no increase in the amount of melanin [20].

(4) Lentiginosis syndromes. A lentigo is defined as having an increase in the number of basal layer melanocytes, without any nests, while a freckle or melanotic spot has an increased amount of melanin alone. Most of the lentiginosis syndromes feature diffuse involvement, such as in LEOPARD syndrome, Carney syndrome, Peutz-Jeghers syndrome and occasionally diffuse lentiginosis without associated disorders. Patients with phosphatase and tensin homolog disorders, especially BannayanRiley-Ruvalcaba syndrome and Cowden syndrome, may have speckled macules on their genitalia [21]. Another possibility is lentiginosis profusa perigenito-axillaris, a rare disorder that, to the best of our knowledge, has been reported only once by Korting [22]. An otherwise healthy young man presented pigmented lesions in the axillae and groin which, upon biopsy, showed an increase in the number of basal melanocytes and amount of melanin.

(5) Mucosal melanotic macules. These acquired lesions may be found on the lips, oral mucosa or genitalia. They are usually large irregular patches and do not appear in a reticulate pattern, but early or subtle lesions could be mistaken for DDD. Histo- logically, they feature flat transitional epithelium with an increased amount of basal layer melanin. Laugier-Hunziker syndrome is an acquired disorder with labial macules and longitudinal pigmented nail streaks; rarely, the patients may also display flexural or genital macules [23].

(6) Neurofibromatosis. Axillary freckles (also called Crowe's sign) is one of the diagnostic criteria for neurofibromatosis type 1 [24]. While neurofibromatosis is rarely studied using skin biopsies, both café-au-lait-colored macules and smaller axillary freckles have an increased number of melanocytes, sometimes with giant melanosomes. The term 'freckle' may be a misnomer, as one study indicated the lesions were closer to lentigines with increased numbers of melanocytes [25]. Whenever discrete or reticulate pigmented macules are indentified in a child, one must search for other stigmata of neurofibromatosis.

(7) Other considerations. Sometimes, if other features dominate, such as hyperkeratotic papules on the nape, other diagnoses may be entertained. Some of the early descriptions, such as that by Dowling and Freudenthal [3], also strongly considered Darier disease. In the first description of Galli-Galli disease, the title of the publication even included the possibility of a diagnosis of Darier disease and Grover dis- ease [11]. Piñol Aguadé et al. [26] described a patient in whom these dark, hyperkeratotic lesions and atrophic scars were most prominent and proposed the name 'enfermedad de los puntos pardos' or 'dark-dot disease'. Histologically, when plugged follicles are associated with lacy epithelial strands arising from the follicle wall instead of from the basal layer, one may diagnose a benign follicular tumor such as a trichofolliculoma.

In conclusion, DDD and related disorders are, generally, clinically harmless, but they have given us valuable new insights into the function of the paired keratins 5 and 14 , showing how these molecules are involved, not only in cell adherence, but also in the packaging and transfer of melanin. While mutations in keratin 5 and 14 were first identified in the various forms of EBS, the presence of keratin 5 mutations in EBS with mottled pigmentation provided the first clue to identifying a function in melanin transfer. Thus, this disorder represents almost a biological bridge between more traditional forms of EBS and DDD [27]. While the list of differential-diagnostic possibilities is long, careful clinicalpathologic correlation coupled, in some instances, with genetic studies, usually yields a precise diagnosis.

\section{References}

1 Kim YC, Davis MD, Schanbacher CF, Su WP: Dowling-Degos disease (reticulate pigmented anomaly of the flexures): a clinical and histopathologic study of 6 cases. J Am Acad Dermatol 1999;40:462-467.

2 Behdjet H: Acanthosis nigricans unassociated with malignancy. Bull Soc Fr Dermatol Syphiligr 1932;39:192.

3 Dowling GB, Freudenthal W: Acanthosis nigricans. Br J Dermatol 1938;50:1147-1150.

4 Degos R, Ossipowski B: Dermatose pigmentaire réticulée des plis. Ann Dermatol Syphiligr (Paris) 1954;81:147-151.

5 Smith EL, Dowling GB, Wilson-Jones E: Acquired axillary and inguinal pigmentation: an epidermal naevoid abnormality not to be confused with acanthosis nigricans. Br J Dermatol 1971;85:295-296.

6 Jones EW, Grice K: Reticulate pigmented anomaly of the flexures: Dowling Degos disease, a new genodermatosis. Arch Dermatol 1978;114:1150-1157.
7 Betz RC, Planko L, Eigelshoven S, Hanneken S, Pasternack SM, Bussow H, Van Den Bogaert K, Wenzel J, Braun-Falco M, Rutten A, Rogers MA, Ruzicka T, Nöthen MM, Magin TM, Kruse R: Loss-of-function mutations in the keratin 5 gene lead to Dowling-Degos disease. Am J Hum Genet 2006;78:510-519.

8 Planko L, Böhse K, Höhfeld J, Betz RC, Hanneken S, Eigelshoven S, Kruse R, Nöthen MM, Magin TM: Identification of a keratinassociated protein with a putative role in vesicle transport. Eur J Cell Biol 2007;86:827839.

9 Lugassy J, Itin P, Ishida-Yamamoto A, Holland K, Huson S, Geiger D, Hennies HC, Indelman M, Bercovich D, Uitto J, Bergman R, McGrath JA, Richard G, Sprecher E: Naegeli-Franceschetti-Jadassohn syndrome and dermatopathia pigmentosa reticularis: two allelic ectodermal dysplasias caused by dominant mutations in KRT14. Am J Hum Genet 2006;79:724-730.
$10 \mathrm{Wu}$ YH, Lin YC: Generalized DowlingDegos disease. J Am Acad Dermatol 2007;57: 327-334.

11 Bardach H, Gebhart W, Luger T: Genodermatosis in a pair of brothers: DowlingDegos, Grover, Darier, Hailey-Hailey or Galli-Galli disease? Hautarzt 1982;33:378-383.

12 Braun-Falco M, Volgger W, Borelli S, Ring J, Disch R: Galli-Galli disease: an unrecognized entity or an acantholytic variant of Dowling-Degos disease? J Am Acad Dermatol 2001;45:760-763.

13 Sprecher E, Indelman M, Khamaysi Z, Lugassy J, Petronius D, Bergman R: GalliGalli disease is an acantholytic variant of Dowling-Degos disease. Br J Dermatol 2007; 156:572-574.

14 Jacyk W, Miklaszewska M: Acquired axillary and inguinal pigmentations. Dermatologica 1973;146:262-265.

15 Meyers GA, Orlow SJ, Munro IR, Przylepa KA, Jabs EW: Fibroblast growth factor receptor 3 (FGFR3) transmembrane mutation in Crouzon syndrome with acanthosis nigricans. Nat Genet 1995;11:462-464. 
16 El Shabrawi-Caelen L, Rütten A, Kerl H: The expanding spectrum of Galli-Galli disease. J Am Acad Dermatol 2007;56:86-91.

17 Rebora A, Crovato F: The spectrum of Dowling-Degos disease. Br J Dermatol 1984;110: 627-630.

18 Müller CS, Pföhler C, Tilgen W: Changing a concept - controversy on the confusing spectrum of the reticulate pigmented disorders of the skin. J Cutan Pathol 2009;36:4448.

19 Liu Q, Jiang L, Liu WL, Kang XJ, Ao Y, Sun M, Luo Y, Song Y, Lo WH, Zhang X: Two novel mutations and evidence for haploinsufficiency of the ADAR gene in dyschromatosis symmetrica hereditaria. Br J Dermatol 2006;154:636-642.
20 Davis MD, Weenig RH, Camilleri MJ: Confluent and reticulate papillomatosis (Gougerot-Carteaud syndrome): a minocyclineresponsive dermatosis without evidence for yeast in pathogenesis. A study of 39 patients and a proposal of diagnostic criteria. $\mathrm{Br} \mathrm{J}$ Dermatol 2006;154:287-293.

21 Blumenthal GM, Dennis PA: PTEN hamartoma tumor syndromes. Eur J Hum Genet 2008;16:1289-1300.

22 Korting GW: Histologic iconography. Lentiginosis profusa perigenito-axillaris. Z Haut Geschlechtskr 1967;42:19-22.

23 Mowad CM, Shrager J, Elenitsas R: Oral pigmentation representing Laugier-Hunziker syndrome. Cutis 1997;60:37-39.
24 Crowe FW: Axillary freckling as a diagnostic aid in neurofibromatosis. Ann Intern Med 1964;61:1142-1143.

25 Amer M, Mostafa FF, Nasr AN: Lentiginous macules and patches of neurofibromatosis (an approach to better terminology). J Eur Acad Dermatol Venereol 2001;15:39-42.

26 Piñol Aguadé J, Fernández N: Enfermedad de los puntos pardos: dark dot disease. Med Cutan Ibero Lat Am 1973:7:257-262.

27 Uttam J, Hutton E, Coulombe PA, AntonLamprecht I, Yu QC, Gedde-Dahl T Jr, Fine JD, Fuchs E: The genetic basis of epidermolysis bullosa simplex with mottled pigmentation. Proc Natl Acad Sci USA 1996;93:90799084. 